\title{
The effects of silica fume and hydrated lime on the strength development and durability characteristics of concrete under hot water curing condition
}

\author{
Ali Hamza ${ }^{1, *}$, Shahram Derogar ${ }^{2}$, and Ceren Ince $^{1}$ \\ ${ }^{1}$ Civil Engineering Department, Middle East Technical University, Northern Cyprus Campus, \\ Kalkanl, Güzelyurt, North Cyprus via Mersin 10, Turkey. \\ ${ }^{2}$ Civil Engineering Department, European University of Lefke, Lefke, North Cyprus via Mersin 10, \\ Turkey.
}

\begin{abstract}
Sustainability is considered to be highly important for preserving continued industrial growth and human development. Concrete, being the world's largest manufacturing material comprises cement as an essential binding component for strength development. However, excessive production of cement due to high degree of construction practices around the world frames cement as a leading pollutant of releasing significant amounts of $\mathrm{CO} 2$ in the atmosphere. To overcome this environmental degradation, silica fume and hydrated lime are used as partial replacements to cement. This paper begins with the examination of the partial replacement levels of hydrated lime and silica fume in concrete and their influence on the mechanical properties and durability characteristics of concrete. The effect of hot water curing on concrete incorporated with both silica fume and hydrated lime is also investigated in this paper. The results reported in this paper show that the use of silica fume as a partial replacement material improved both the mechanical properties and durability characteristics of concrete due to the formation of calcium silica hydrate crystals through the pozzolanic reaction. Although the hydrated lime did not significantly contribute in the development of strength, its presence enhanced the durability of concrete especially at long-term. The results also showed that hot water curing enhanced the strength development of concrete incorporated with silica fume due to the accelerated rate of both the hydration and pozzolanic reaction that takes place between silica fume and calcium hydroxide of the cement matrix particularly at early times. The results reported in this paper have significant contribution in the development of sustainable concrete. The paper does not only address the use of alternative binders as a partial replacement material in concrete but also suggest proper curing conditions for the proposed replacement materials. These practices play a vital role in the development of sustainable concrete.
\end{abstract}

\footnotetext{
* Corresponding author: ali.hamza@metu.edu.tr
} 


\section{Introduction}

Recent developments in the construction industry has promoted concrete as 'highly efficient material with improved mechanical properties and durability' [1]. However, such advancements have also highlighted cement and concrete manufacturing as carbon and energy intensive processes. It has been claimed that up to $5-9 \%$ of the total global anthropogenic carbon emissions [2,3] are due to manufacturing of cement and concrete. Furthermore, concrete is not an everlasting building material when analyzed against time. Eventually, the life cycle of concrete will end up as limestone, sand and clay within our earth's environment [1]. Therefore, the significant issue of improving durability and service life of concrete is always crucial to have its attention [4]. From the idea of sustainability in concrete manufacturing, there is a need to develop an environmentally friendly type building material which ensures a good balance between performance and sustainability concern $[5,6]$. With the extensive use of Portland cement, it is inevitable that such idea of sustainable concrete can be accomplished. However, if the cement manufacturing is tend to shift with the mixture of 'second generation' or 'low carbon' binders [7], the idea of achieving sustainable concrete may emerge to existence.

In various recent studies, it has been addressed that hydraulic lime and supplementary cementitious materials (SCMs) do possess essential properties that leads towards strength development and enhancement of durability of concrete. [8-11]. Hydraulic lime, being one of the oldest binders contributes substantial history in construction practices and manufacturing [7]. Furthermore, SCMs broadly pozzolans, have also been considered as a viable approach to be used as an alternative binder [7]. Pozzolans normally results in poor performance and low strength development at early stages due to absence of adequate quantities of $\mathrm{Ca}(\mathrm{OH})_{2}$ [12]. To overcome such issue of strength development and durability, possibilities for improving the pozzolanic reaction by adding hydrated lime have been mentioned in the literature [13-19]. Silica fume, being one of the most popular pozzolans is considered to play a vital role in developing strength, durability characteristics and consuming calcium hydroxides during the hydration reaction of Portland cement [18, 20, 21]. Therefore, such pozzolanic reactions may contribute to lower heat liberation, adequate early strength development, effective consumption of hydrated lime and enhancement in durability characteristics $[6,18]$.

Replacing Portland cement with hydrated lime and pozzolans such as silica fume does not solve this complex issue. Since, each binder has its own chemical reaction, it is important to highlight the significance of curing time and conditions. Cement hydration completes in 28 days as cement attains its compressive strength. However, lime carbonation is comparatively a slower reaction. Even though, pozzolanicity does have the ability to consume calcium hydroxide to form calcium silicate hydrate $(\mathrm{C}-\mathrm{S}-\mathrm{H})$ which is essential for strength development, especially at early stages [17], the rate of reaction is also comparatively slower. In addition to that, it has also been criticized that various experimental studies conducted on concrete incorporated with hydrated lime and pozzolans have been cured for short interval of time. The results may vary if the curing period was much longer [22] and/or the curing conditions have been provided in a different way such as the introduction of hot water curing or steam curing conditions [23].

Therefore, the aim of this paper is to offer a holistic approach of using hydrated lime and silica fume as partial replacement of Portland cement as binders. The idea is to investigate the possible role of hydrated lime and silica fume used as a partial replacement to cement on the strength development and durability characteristics. Strength development includes compressive strength test as a key parameter being investigated. Tests such as water permeability and freezing/thawing resistance for determining the pore structure of concrete are included in the durability characteristics. The possible effect of hot water 
curing conditions is also highlighted addressing the significant role on strength development and durability characteristics of the concrete.

\section{Materials and mix design}

The experimental study was conducted on freshly-mixed and hardened state concrete using Portland cement, hydrated lime (CL80) and Silica Fume as binders. Portland cement was acquired from Adana Cimento Ltd. and complies with [24]. CL80 was obtained from Nur Kirec Ltd. and complies with [25]. The designation of CL80 indicates the calcium lime content is not greater than $80 \%$. Silica Fume was acquired from Cyprus Environmental Enterprises Ltd. (CEE) and complied with [26]. Apart from binders, other elements of concrete prepared include fine aggregates, coarse aggregates and water. Particle size distribution of fine aggregates and coarse aggregates have been made accordance with [27]. Various replacement levels of CL80 and silica fume were used to investigate the influential role on the fresh and harden state properties of Portland cement concrete. For mix design calculations, the slump value has been kept constant to $100 \mathrm{~mm}$. Therefore, the water/binder $(\mathrm{w} / \mathrm{b})$ ratio have been adjusted accordingly. The masses of binders required to produce the necessary mix proportions by volume were calculated from carefully determined values of relative density. For fine and coarse aggregates, specific gravity was determined according to $[28,29]$.

\section{Experimental procedures}

\subsection{Measurement of slump}

The slump of fresh concrete prepared containing various volume fraction replacement levels of CL80 and silica fume was measured using the standard slump test apparatus. The slump value has been determined as per [30]. The slump value has been kept constant to $100 \mathrm{~mm}$. By keeping such consistency of slump value, the water/binder ratio has been kept between the ranges of 0.50 to 0.70 .

\subsection{Curing conditions}

Two types of curing conditions have been investigated for curing processes of concrete. A normal portable water curing condition having water temperature of $20^{\circ} \mathrm{C}$ is maintained. Furthermore, hot water curing condition having water temperature to $40^{\circ} \mathrm{C}$ is additionally kept up. Curing conditions have been standardized as per [31].

\subsection{Measurement of compressive strength}

Compressive strength testing was conducted on various hardened replacement levels of concrete including CL80 and silica fume respectively. The testing has been conducted from 28 days to 180 days on $150 \mathrm{~mm}$ standard cubes. Samples of each replacement level were tested using a compressive testing machine. The loading rate has been kept constant to 0.6 $\mathrm{MPa} / \mathrm{sec}$. An average compressive strength has been taken among all the values from each replacement level of concrete produced in accordance with [32]. 


\subsection{Measurement of water permeability}

Standard cubes of $150 \mathrm{~mm}$ were used for determining the water permeability for each replacement level of concrete produced. Each specimen was fixed into the permeability testing machine and pressurized water has been applied from the bottom of the specimen. Adjustment of the sample is important on the permeability machine to avoid water leakage from the sides of the specimen. All specimens were subjected to 1 atmospheric pressure $(0.1 \mathrm{MPa})$. It is important to mention that the mass measurements before and after the water permeability test should be taken to understand each specimen's water infiltration capacity. After 72 hours, each specimen was removed from the permeability machine and split into two equal halves for determining the water penetration depth. Average depth was taken from four equidistant spots along the bottom of the specimen from where the water pressure has been applied. The experiment is done based on [33].

\subsection{Measurement of freeze and thaw resistance}

For freeze and thaw cycles, cube samples of $150 \mathrm{~mm}$ have been placed in freeze and thaw cabinet. Similar procedure has been followed as reported by [34]. It includes freezing and thawing phenomenon for the cured samples of various replacement levels at $-30^{\circ} \mathrm{C}$ to $30^{\circ} \mathrm{C}$. Two cycles have been maintained on a daily basis. Within $12 \mathrm{~h}$ each day, the samples have been experiencing freezing and thawing automatically when the temperature reaches $-30^{\circ} \mathrm{C}$ or $30^{\circ} \mathrm{C}$. The cycle keeps on going twice a day from the last 180 days. The relative humidity is maintained ranging from $85 \%$ to $95 \%$. It is important to mention that the surface of the samples have not been covered during the freezing and thawing, so that the sample is fully exposed to moisture changes.

\section{Experimental results}

\subsection{Mechanical properties}

\subsubsection{Influence of silica fume on the compressive strength of concrete}

The influence of the use of silica fume as a partial replacement to cement on the compressive strength of concrete is investigated in this section. Replacement levels of silica fume were 10 and $20 \%$. The samples under investigation were cured under water at the laboratory conditions for 180 days. The influence of the use of silica fume on the compressive strength of concrete is shown in Figure 1.

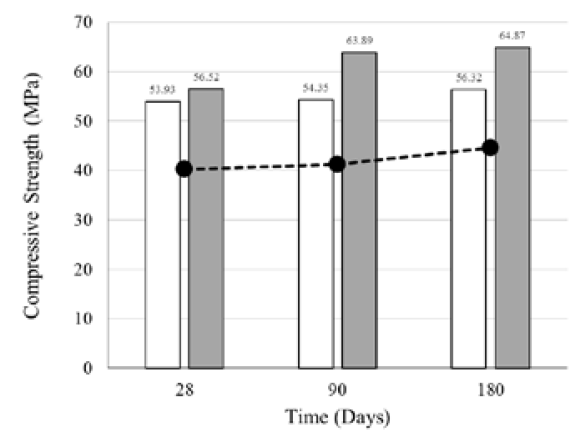

Fig. 1. Influence of silica fume on the compressive strength of concrete $\square ; 20 \%$ silica fume, $\square ; 10 \%$ silica fume and $\bullet$; concrete control specimen. 
It is shown in Figure 1 that the use of silica fume resulted in an increase in the compressive strength of concrete over the 180 days when compared to the control concrete specimen. However, the increase in the replacement levels of silica fume resulted in a decrease in the compressive strength. A very hydraulic binder, cement, is being replaced with a pozzolanic material that reduces the rate of hydration reaction specifically at short terms. The development of the concrete strength after 28 days is solely depending on the pozzolanic reaction between the calcium hydroxide and the silica fume. It can be seen in Figure 1 that at each replacement level, the compressive strength of concrete is increasing with time. It must be underlined that both replacement levels of silica fume resulted in a greater compressive strength of concrete with time.

\subsubsection{The effect of hot water curing on the strength development of concrete incorporated with silica fume}

The effect of hot water curing on the strength development of concrete incorporated with silica fume is investigated in this section. The effect of hot water curing is used particularly for the early strength development of pozzolanic reaction which has much slower rate than cement hydration. The effect of hot water curing on the compressive strength of concrete with $10 \%$ replacement level of silica fume is shown in Figure 2.

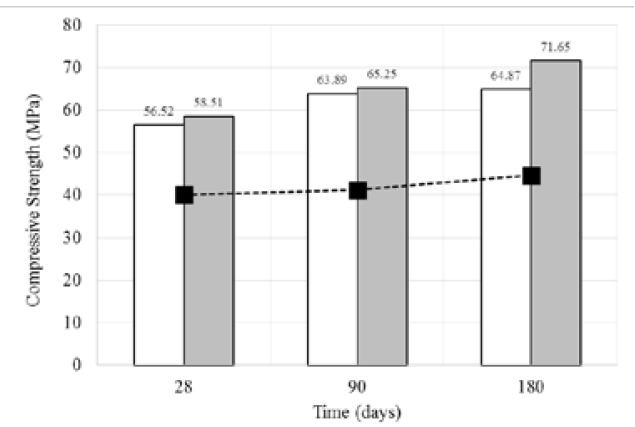

Fig. 2. The effect of hot water curing on the strength development of concrete incorporated with $10 \%$ silica fume $\square$; cold water cured, $\square$; hot water cured, $\bullet$; concrete control specimen.

It can be seen in Figure 2 that hot water curing enhanced the strength development of pozzolanic concrete. The increase in the compressive strength of concrete incorporated with $10 \%$ silica fume is more markedly seen in 6 months. It is well known that pozzolanic reaction is depended on the hydration reaction and hence the formation of calcium hydroxide. The effect of hot water curing on the strength development of concrete therefore cannot yet be seen at 28 days. It must be underlined however that hot water curing enhanced the compressive strength of concrete incorporated with $10 \%$ silica fume at 3 and 6 months significantly.

\subsubsection{The effect of using hydrated lime on the strength development of concrete incorporated with silica fume}

In this section, cement is partially replaced with silica fume and hydrated lime. Replacement level of silica fume was kept constant to $20 \%$ while the replacement levels of hydrated lime were 10 and $20 \%$. The effect of using hydrated lime on the 
compressive strength of concrete incorporated with silica fume cured under both cold and hot water conditions is shown in Figure 3.

It can be seen in Figure 3 that the use of hydrated lime as a replacement to cement resulted in a decrease in compressive strength of concrete incorporated with silica fume. Compressive strength of concrete replaced with hydrated lime and silica fume, however is increasing with time. The increase in the compressive strength is mainly due to the presence of calcium hydroxide in the cement matrix that accelerated the rate of the pozzolanic reaction. It can be seen in Figure 3 that at 6 months, the compressive strength of concrete at all combinations are higher that the compressive strength of the control specimen at $28^{\text {th }}$ days. Hot water curing also resulted in an increase in the compressive strength of concrete at both replacement levels of hydrated lime.

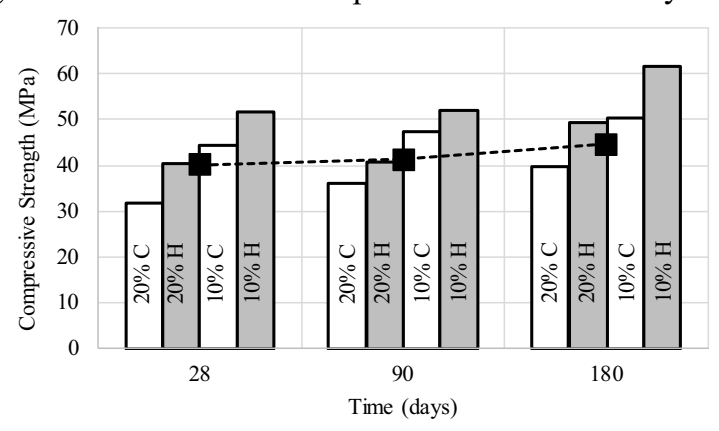

Fig. 3. The effect of using hydrated lime on the compressive strength of concrete incorporated with silica fume cured under both cold and hot water conditions $\bullet$; concrete control specimen, C; cold water curing, $\mathrm{H}$; hot water curing.

\subsection{Water permeability}

\subsubsection{The effect of using hydrated lime on the water permeability of concrete incorporated with silica fume}

The effect of using hydrated lime and silica fume on the water permeability of concrete is investigated in this section. Concrete specimen with $20 \%$ replacement level of silica fume is considered first in this study. Concrete specimen with $20 \%$ replacement level of silica fume and $20 \%$ replacement level of hydrated lime is then used to study the freeze and thaw resistance of concrete. Concrete control specimen is also subjected to the analysis for the comparison reason. Water penetration depth (mm) versus time (days) for concrete samples are shown in Figure 4.

It can be seen in Figure 4 that the use of $20 \%$ silica fume as a replacement to cement resulted in a dramatic decrease in water penetration depth of concrete at 3 and 6 months. These results are in good agreement with the strength development of concrete incorporated with $20 \%$ silica fume. The great reduction in water penetration depth of concrete and hence the increase resistance to water permeability can be attributed to the pozzolanic reaction and therefore the consumption of calcium hydroxide and thus the formation of more of calcium silica hydrate gels that enhances the resistance to water permeability of concrete at long-term. 


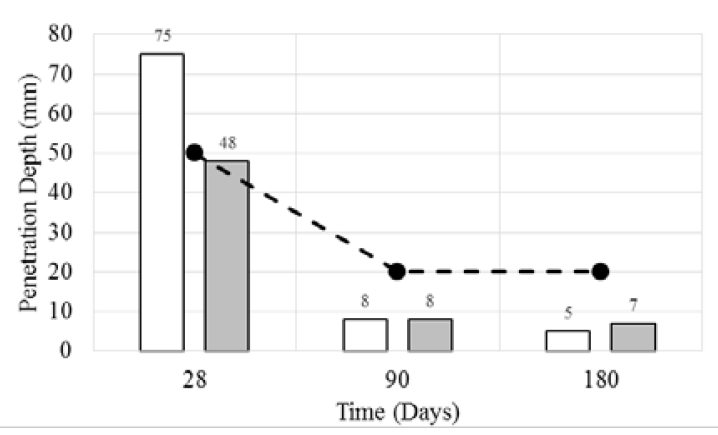

Fig. 4. Effects of using hydrated lime and silica fume on the water permeability of concrete $\square ; 20 \%$ silica fume, $\square ; 20 \%$ silica fume with $20 \%$ hydrated lime, $\bullet$; concrete control specimen.

It can also be seen in Figure 4 that the use of $20 \%$ hydrated lime in concrete incorporated with $20 \%$ silica fume is also leading a great reduction in water penetration depth of concrete. Even at $28^{\text {th }}$ days, there is a remarkable decrease in water penetration depth of concrete when hydrated lime is used in concrete incorporated with silica fume. Since the particle size of silica fume and hydrated lime are much finer than the cement binder, filler effect must played a significant role in the resistance to water penetration of concrete. It must be underlined that at 180 days, the concrete specimen prepared using $20 \%$ silica fume and $20 \%$ hydrated lime resulted in a great reduction in water penetration depth and hence resulted in an enhanced resistance of water penetration of concrete.

\subsection{Freeze and thaw resistance}

\subsubsection{The effect of silica fume on the freeze and thaw resistance of concrete}

The effect of silica fume on the freeze and thaw resistance of concrete is investigated in this section. Cement replacement level of 10 and $20 \%$ of silica fume is used to study the freeze and thaw resistance to concrete. Following cured at laboratory conditions for 28 days, the specimens were subjected to cycling freeze and thaw for 28,90 and 180 days.

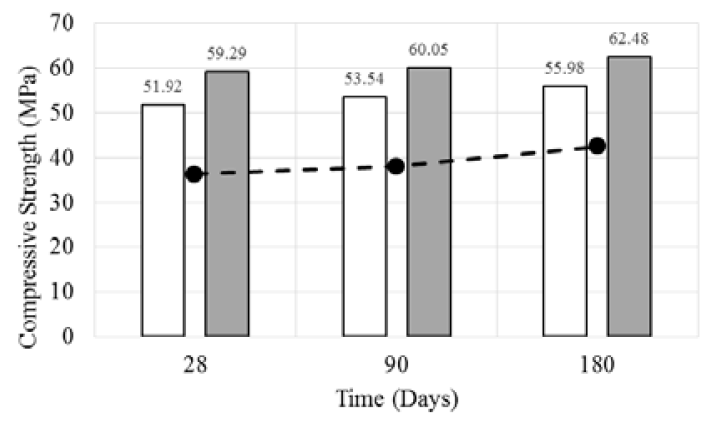

Fig. 5. Effects of silica fume on the freeze and thaw resistance of concrete $\square$; $10 \%$ silica fume, $\square$; $20 \%$ silica fume, $\bullet$; concrete control specimen. 
Figure 5 shows the compressive strength of concrete incorporated with silica fume that are subjected to freeze and thaw cycles. The concrete control specimen that is subject to freeze and thaw is also shown in Figure 5 for comparison reason. It can clearly be seen in Figure 5 that the increase in the replacement level of silica fume resulted in an increase resistance to freeze and thaw. In increase in the replacement level of silica fume resulted in an increased rate of pozzolanic reaction that takes place between the calcium hydroxide and the silica and hence resulted in great formation of calcium silicate hydrate gels. The increase in compressive strength lead to a higher resistance to freeze and thaw of concrete.

\subsubsection{The effect of using hydrated lime on the freeze and thaw resistance of concrete incorporated with silica fume}

The effect of using hydrated lime on the freeze and thaw resistance of concrete incorporated with silica fume is investigated in this section. Figure 6 show compressive strength of concrete specimens subjected to freeze and thaw for 28, 90 and 180 days. It can be seen in Figure 6 that the use of $10 \%$ hydrated lime with $20 \%$ silica fume resulted in a greater resistance to freeze and thaw resistance however, when the replacement level of hydrated lime is increased to $20 \%$, the resistance to freeze and thaw was identical to the concrete control specimen. The main reason for this behavior is attributed to the decrease in the overall strength of concrete when $20 \%$ hydrated lime is used as a replacement level.

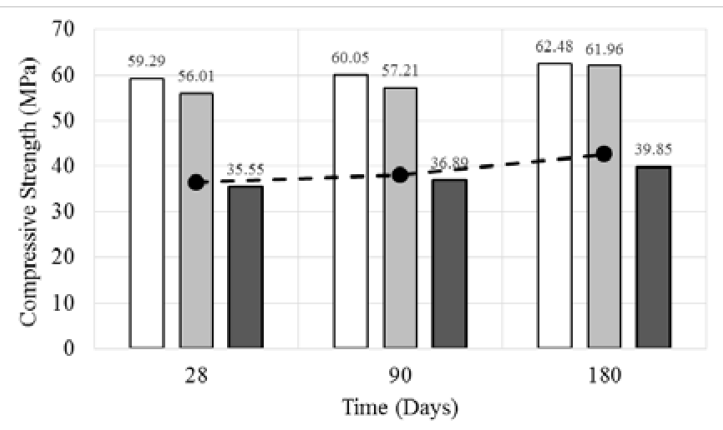

Fig. 6. Effects of using hydrated lime and silica fume on the freeze and thaw resistance of concrete $\square$; $20 \%$ silica fume, $\square ; 20 \%$ silica fume with $10 \%$ hydrated lime, $\square ; 20 \%$ silica fume with $20 \%$ hydrated lime, $\bullet$; concrete control specimen.

\section{Conclusion}

The paper investigates the use of silica fume and hydrated lime as a replacement material to cement on the strength development and durability of concrete. The effect of hot water cure condition on the strength development of concrete incorporated with silica fume and hydrated lime is also investigated in this paper. The results show that the use of silica fume enhance the compressive strength of concrete especially at longterm. It is also shown in this paper that the hot water cure condition played a significant role in the strength development of concrete incorporated with silica fume. Although the use of hydrated lime might result in a decrease in compressive strength of concrete at short-terms, the compressive strength of concrete with all combinations of silica fume and hydrated lime at 6 months are higher that the compressive strength of the control specimen at $28^{\text {th }}$ days. It is also shown in the paper that the hot water curing 
also resulted in an increase in the compressive strength of concrete at both replacement levels of hydrated lime. The use of silica fume and hydrated lime decreased the water penetration depth of concrete and enhance the water permeability of concrete dramatically. The increase in the replacement level of silica fume resulted in an increased resistance to freeze and thaw resistance of concrete. Although the use of $10 \%$ hydrated lime enhanced the freeze and thaw resistance of concrete incorporated with silica fume, freeze and thaw resistance of concrete with $20 \%$ replacement level of lime was equivalent to the resistance of concrete control specimen. Thus, by these results, we can summarize that the role of hydrated lime, silica fume along with hot curing conditions not only contribute towards required mechanical properties and enhanced durability characteristics. It also creates a new way to use these neglected materials and conditions to promote the idea of sustainable construction.

\section{References}

1. Aitcin, P.C., The durability characteristics of high performance concrete: a review. Cement and Concrete Composites, 25(4), 409-420 (2003)

2. Shi, C., Jiménez, A.F. and Palomo, A., New cements for the 21 st century: the pursuit of an alternative to Portland cement. Cement and concrete research, 41(7), 750-763 (2011)

3. Harrison, A.J.W., Low carbon cements and concrete in modern construction. In UKIERI Concrete Congress-Innovations in Concrete Construction, Jalandhar, 723746 (2013).

4. Sun, W., Zhang, Y.M., Yan, H.D. and Mu, R., Damage and damage resistance of high strength concrete under the action of load and freeze-thaw cycles. Cement and Concrete Research, 29(9), 1519-1523 (1999)

5. Sharma, A. and Rani, A., Green concrete and its demand on the sustainable construction industry. International Journal of Engineering Science Invention Research and Development, 2(2), 472-480 (2016)

6. Garg, C. and Jain, A., Green Concrete: Efficient \& Eco-Friendly Construction Materials. International journal of research in engineering and technology, 2(2), 259264 (2014)

7. Grist, E.R., Paine, K.A., Heath, A., Norman, J. and Pinder, H., The environmental credentials of hydraulic lime-pozzolan concretes. Journal of Cleaner Production, 93, 26-37 (2015)

8. Hooton, R.D. and Bickley, J.A., Design for durability: the key to improving concrete sustainability. Construction and Building Materials, 67, 422-430 (2014)

9. Bentz, D.P., Hansen, A.S. and Guynn, J.M., Optimization of cement and fly ash particle sizes to produce sustainable concretes. Cement and Concrete Composites, 33(8), 824-831 (2011)

10. Zhang, T., Yu, Q., Wei, J. and Zhang, P., Efficient utilization of cementitious materials to produce sustainable blended cement. Cement and Concrete Composites, 34(5), 692699 (2012)

11. Barbhuiya, S.A., Gbagbo, J.K., Russell, M.I. and Basheer, P.A.M., Properties of fly ash concrete modified with hydrated lime and silica fume. Construction and Building Materials, 23(10), 3233-3239 (2009)

12. Hardtl, R. and Zement, H., The pozzolanic reaction of fly ash in connection with different types of cement. In Proceedings of the 10th International Conference on Chemistry of Cement, 101, 8-15 (1997) 
13. Loughborough, M.T., Mukherjee, P.K. and Malhotra, V.M., Development of highstrength concrete incorporating a large percentage of fly ash and superplasticizers. Cement, Concrete and Aggregates, 4(2), 81-86 (1982)

14. Mehta, P.K., Pozzolanic and cementitious by-products in concrete--another look. Special Publication, 114, 1-44 (1989)

15. Ghosh, S.N., Sarkar, S.L. and Harsh, S., Mineral admixtures in cement and concrete. Abi Books (1993)

16. Mira, P., Papadakis, V.G. and Tsimas, S., Effect of lime putty addition on structural and durability properties of concrete. Cement and concrete research, 32(5), 683-689 (2002)

17. Juenger, M.C. and Siddique, R., Recent advances in understanding the role of supplementary cementitious materials in concrete. Cement and Concrete Research, 78, 71-80 (2015)

18. Mazloom, M., Ramezanianpour, A.A. and Brooks, J.J., Effect of silica fume on mechanical properties of high-strength concrete. Cement and Concrete Composites, 26(4), 347-357 (2004)

19. Ozturk, Y., 2011. The use of supplementary cementing materials in the manipulation of mix water transport in mortar-masonry systems. MPhil Thesis, The University of Manchester, UK

20. Fidjestøl, P. and Dåstøl, M., The history of silica fume in concrete-From novelty to key ingredient in high performance concrete. In Proceedings of the Congresso Brasileiro do Concreto. 4th-9th Sept 2008. Salvador: El Salvador (2008)

21. Elahi, A., Basheer, P.A.M., Nanukuttan, S.V. and Khan, Q.U.Z., Mechanical and durability properties of high performance concretes containing supplementary cementitious materials. Construction and Building Materials, 24(3), 292-299 (2010)

22. Toutanji, H., Delatte, N., Aggoun, S., Duval, R. and Danson, A., Effect of supplementary cementitious materials on the compressive strength and durability of short-term cured concrete. Cement and Concrete Research, 34(2), 311-319 (2004)

23. Chithra, S. and Dhinakaran, G., Effect of hot water curing and hot air oven curing on admixed concrete. International Journal of ChemTech Research CODEN (USA): IJCRGG, 1516-1523 (2014)

24. ASTM C150/C150M-16e1 Standard Specification for Portland Cement, ASTM International, West Conshohocken, PA (2016)

25. BS EN 459-1. Building Lime. Definitions, specifications and conformity criteria. London: BSI (2015)

26. ASTM C1240-15 Standard Specification for Silica Fume Used in Cementitious Mixtures, ASTM International, West Conshohocken, PA (2015)

27. ASTM C33/C33M-16e1 Standard Specification for Concrete Aggregates, ASTM International, West Conshohocken, PA (2016)

28. ASTM C127-15 Standard Test Method for Relative Density (Specific Gravity) and Absorption of Coarse Aggregate, ASTM International, West Conshohocken, PA (2015)

29. ASTM C128-15 Standard Test Method for Relative Density (Specific Gravity) and Absorption of Fine Aggregate, ASTM International, West Conshohocken, PA (2015)

30. ASTM C143/C143M-15a Standard Test Method for Slump of Hydraulic-Cement Concrete, ASTM International, West Conshohocken, PA (2015)

31. ASTM C192/C192M-16a Standard Practice for Making and Curing Concrete Test Specimens in the Laboratory, ASTM International, West Conshohocken, PA (2016)

32. BS EN 12390-3. Testing hardened concrete. Compressive strength of test specimens. London: BSI (2002) 
33. BS EN 12390-8. Testing hardened concrete. Depth of penetration of water under pressure. London: BSI (2009)

34. Khoury, N.N. and Zaman, M.M., Environmental effects on durability of aggregates stabilized with cementitious materials. Journal of Materials in civil Engineering, 19(1), 41-48 (2007) 